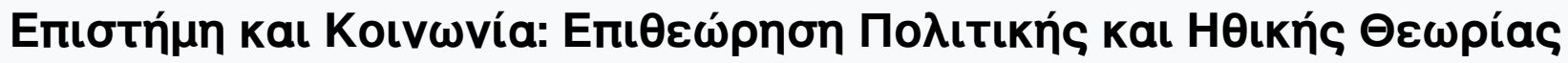

Tóp. 7 (2001)

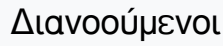

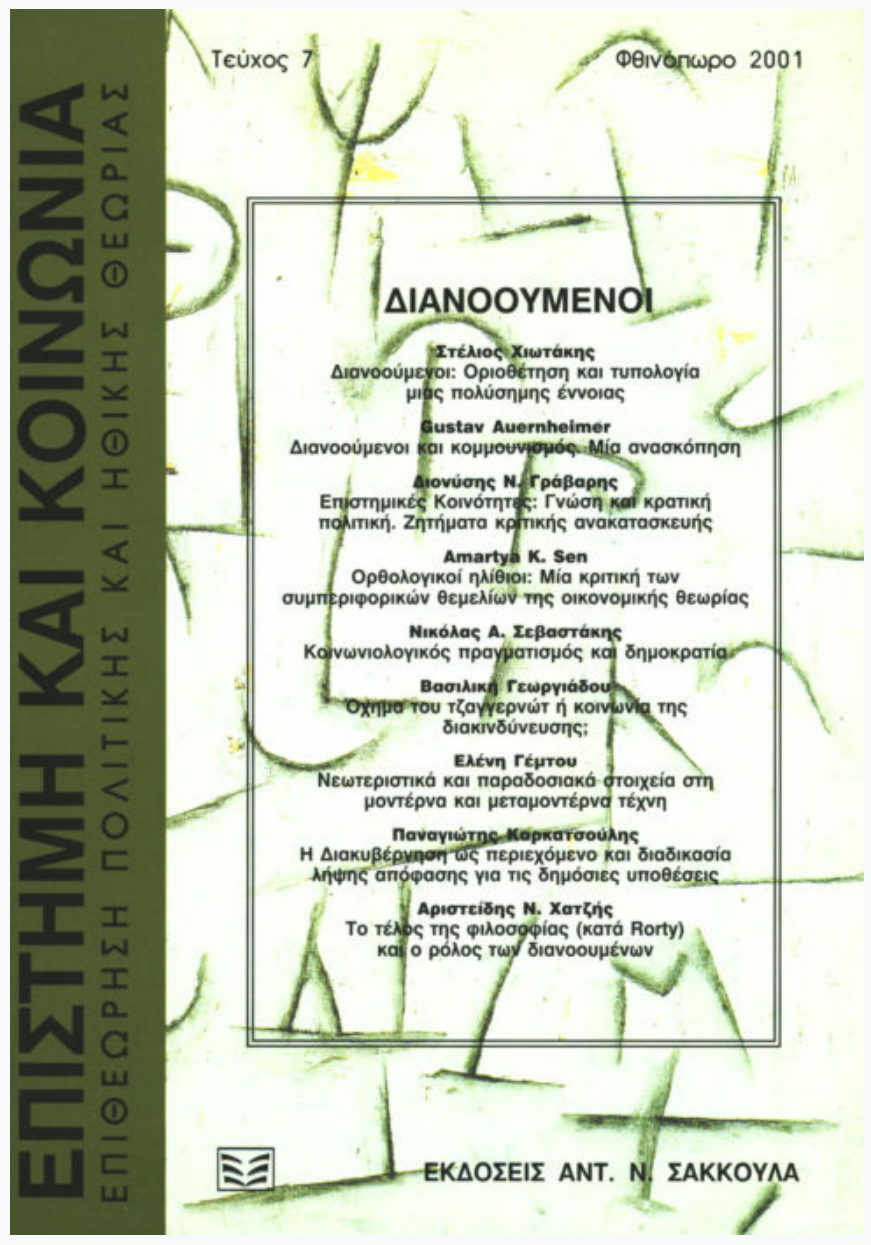

\section{Zygmunt Bauman, Liquid Modernity}

B. Г.

doi: $\underline{10.12681 / \text { sas. } 638}$

Copyright (C) 2015, B. Г.

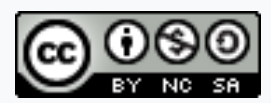

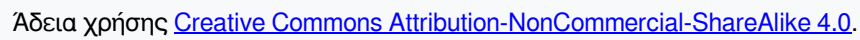

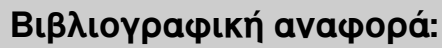

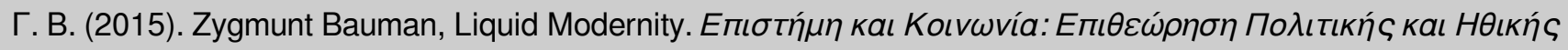
Oewpías, 7, 257-258. https://doi.org/10.12681/sas.638 


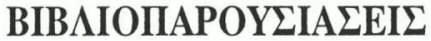

Zygmunt Bauman, Liquid Modernity, Cambridge: Polity Press, 2000, 228 $\sigma \varepsilon \lambda$.

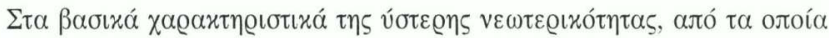

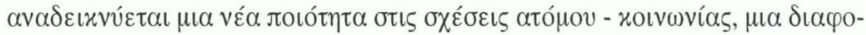

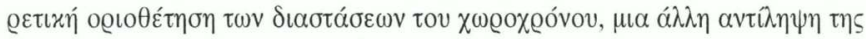

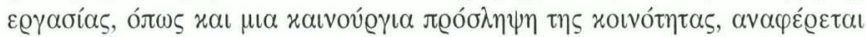

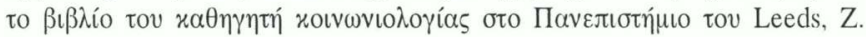
Bauman.

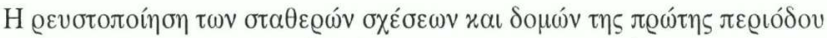

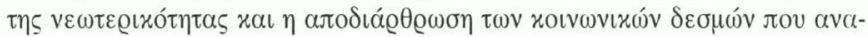

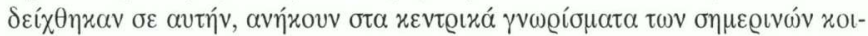

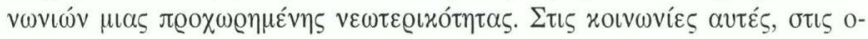

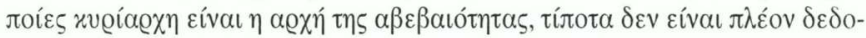

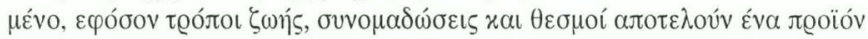

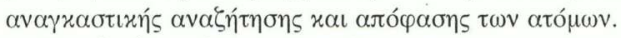

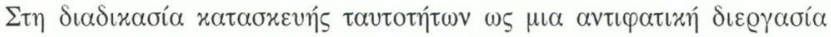

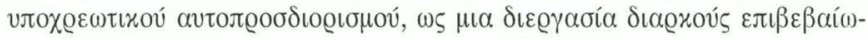

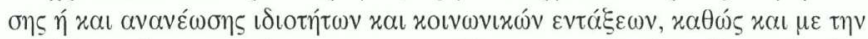
$\alpha v \alpha \zeta \eta ́$ ๆๆ

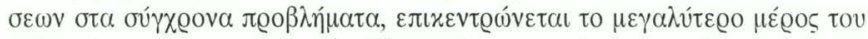

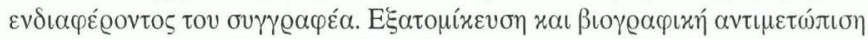

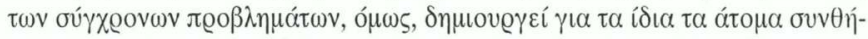

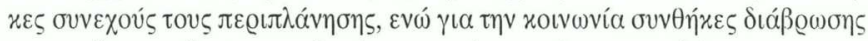

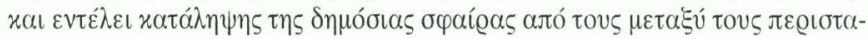

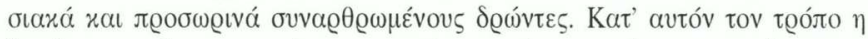

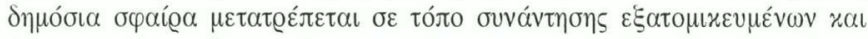

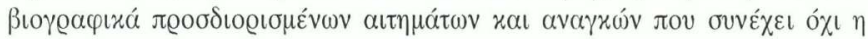




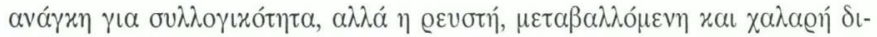

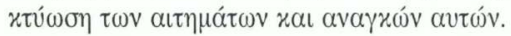

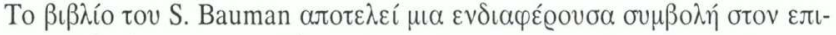

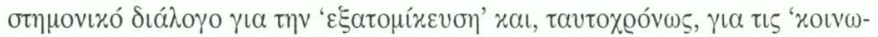

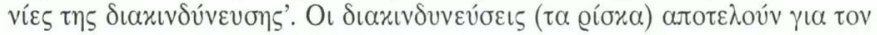

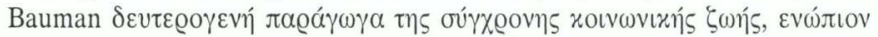

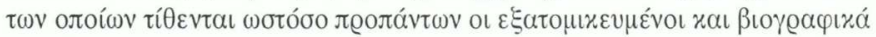

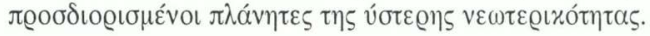

B.Г.

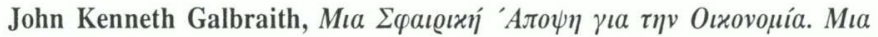

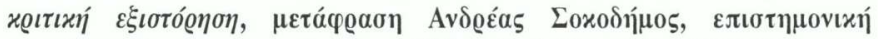

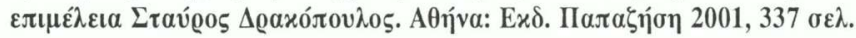

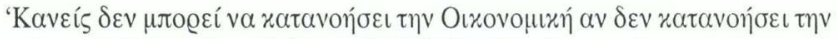

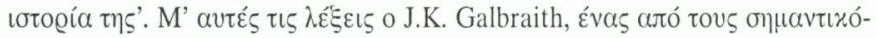

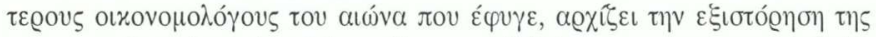

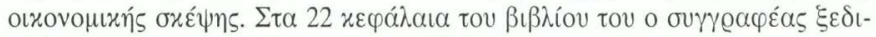

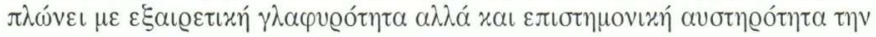

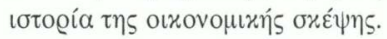

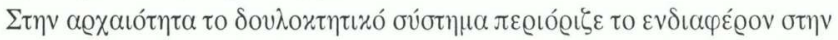

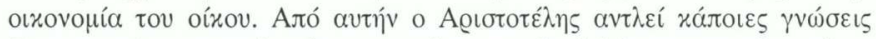

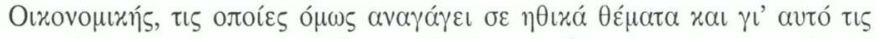

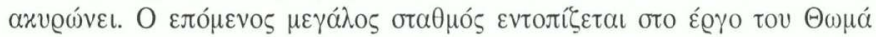

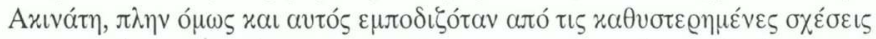

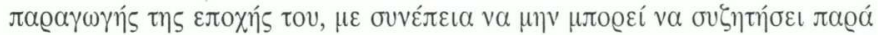

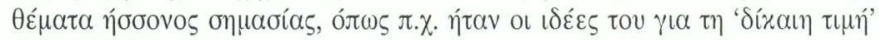
$\tau \omega v \alpha \gamma \alpha \theta \omega \dot{v}$.

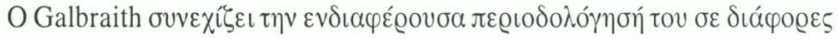

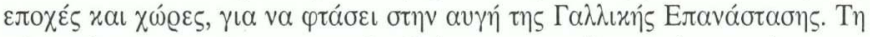

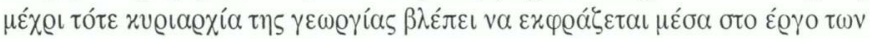

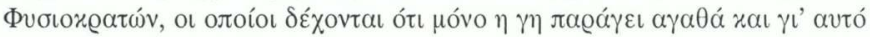

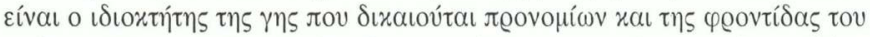

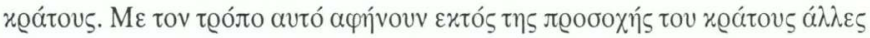

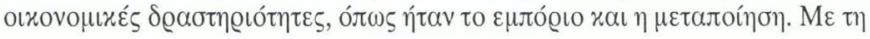

